\title{
CULTURA DIGITAL: TECNOLOGIAS, ESCOLA E NOVAS PRÁTICAS EDUCATIVAS
}

\author{
DIGITAL CULTURE: TECHNOLOGIES, SCHOOL AND NEW \\ EDUCATIONAL PRACTICES \\ CULTURA DIGITAL: TECNOLOGÍAS, ESCUELA Y NUEVAS \\ PRÁCTICAS EDUCATIVAS
}

Maria do Socorro Souza*

(iD http://orcid.org/oooo-0oo3-2373-6101

Paulo Augusto Tamanini**

(D) https://orcid.org/oooo-ooo1-6963-2952

Jean Mac Cole Tavares Santos***

(iD) http://orcid.org/oooo-ooo1-780o-8350

\author{
REVISTA PEDAGÓGICA \\ Revista do Programa de Pós-graduação em Educação da Unochapecó | ISSN 1984-1566 \\ Universidade Comunitária da Região de Chapecó | Chapecó-SC, Brasil \\ Como referenciar este artigo: SOUZA, M. S; TAMANINI, P. A; SANTOS, J. M. C. T. \\ Cultura digital: tecnologias, escola e novas práticas educativas. Revista Pedagógica, Chapecó, v. 22, p. 1-19, 2020. \\ DOI: http://dx.doi.org/10.22196/rp.v22io.4771
}

\begin{abstract}
Resumo: Este estudo, de cunho bibliográfico, discute a inserção das tecnologias digitais na educação, especialmente no ensino de História, no contexto da cultura digital e as novas demandas teóricometodológicas por ela exigidas, a fim de desenvolver a criticidade no uso das tecnologias, seja ao consumir, circular ou produzir conteúdo, visando à formação cidadã do aluno. Sob a perspectiva teórica dos Estudos Culturais, o texto aborda a cultura digital, seu conceito e características, a partir das mudanças culturais ocorridas nos últimos tempos, causadas pela revolução tecnológica e a consequente centralidade da cultura nesse contexto. Autores como Hall (1997), Heinsfeld e Pischetola (2017), Bortolazzo (2016), Lévy (1996, 1999), Arruda $(2013,2014)$ e Lemos $(2003,2008,2009)$ serviram de referencial teórico para o debate. Pode-se concluir que a adequação da escola à cultura digital abrange bem mais do que a mera inserção dos artefatos digitais na prática pedagógica, exigindo profundas mudanças nos modelos pedagógicos vigentes.
\end{abstract}

Palavras-chave: Tecnologias Digitais. Cultura Digital. Estudos Culturais. Educação. Ensino de História.

Abstract: This bibliographical study discusses the insertion of digital technologies in education, specially in the History teaching, in the context of digital culture and the new theoretical and methodological demands required by it, in order to develop criticality in the use of technologies, whether consuming, circulating or producing content, aiming at the citizen's formation of the student. Under the theoretical perspective of Cultural Studies, the text approaches digital culture, its concept and characteristics, based on the cultural changes that have occurred in recent times, caused by the technological revolution and the consequent centrality of culture in this context. Authors such as Hall (1997), Heinsfeld and Pischetola (2017), Bortolazzo (2016), Lévy (1996, 1999) and Arruda $(2013,2014)$ form the theoretical basis for the discussion. It can be concluded that the adequacy of the school to the digital culture covers much more than the mere insertion of the digital artifacts in the pedagogical practice, requiring profound changes in the existing pedagogical models.

Keywords: Digital Technologies. Digital Culture. Cultural Studies. Education. History Teaching.

Resumen: Este estudio, de cuño bibliográfico, discute la inserción de las tecnologías digitales en la educación, especialmente en la enseñanza de Historia, en el contexto de la cultura digital y las nuevas demandas teóricometodológicas por ella exigidas, a fin de desarrollar la criticidad en el uso de las tecnologías, sea al consumir, circular o producir contenido, con el objetivo de la formación ciudadana del alumno. Bajo la perspectiva teórica de los Estudios Culturales, el texto aborda la cultura digital, su concepto y características, a partir de los cambios culturales ocurridos en los últimos tiempos, causados por la revolución tecnológica y la consecuente centralidad de la cultura en ese contexto. Los autores como Hall (1997), Heinsfeld y Pischetola (2017), Bortolazzo (2016), Lévy (1996, 1999), Arruda (2013, 2014) y Lemos (2003, 2008, 2009) sirvieron de referencial teórico para el debate. Se puede concluir que la adecuación de la escuela a la cultura digital abarca mucho más que la mera inserción de los artefactos digitales en la práctica pedagógica, exigiendo profundos cambios en los modelos pedagógicos vigentes.

Palabras clave: Tecnologías Digitales. Cultura Digital. Estudios Culturales. Educación. Enseñanza de Historia. 


\section{Introdução}

O contexto histórico contemporâneo é marcado por transformações vertiginosas em todas as suas esferas - social, econômica, política, cultural, educacional etc. -, pautadas na conectividade, ubiquidade, interatividade, comunicação multidirecional, informação em tempo real, descentralização e democratização da informação e das comunicações, o que vem reestruturando a sociedade, tanto em suas instituições como nas relações entre as pessoas. Esse novo cenário retrata a cultura digital que se dissemina aceleradamente e cujo sustentáculo são as tecnologias digitais, notadamente a internet, com suas múltiplas ferramentas e linguagens. Produtos e produtores da cultura, esses artefatos digitais criam inovações no âmbito comunicacional, informacional e interacional, bem como influenciam no processo de produção e construção do conhecimento, possibilitando uma nova dinâmica relacional entre o homem, o conhecimento, as tecnologias e o mundo que o circunda.

Novas linguagens e gêneros textuais, redes sociais virtuais, hipertexto, produção e compartilhamento de conteúdo em rede e em tempo real e construção colaborativa do conhecimento, simulações de realidades virtuais são apenas alguns exemplos de como as tecnologias digitais ajudam a construir sentidos, influenciando na formação de identidades e na representação do mundo, dos objetos e dos seres que nele habitam na cultura digital. Nesse sentido, cabe à escola inserir esses artefatos em sua prática cotidiana, de modo a se aproximar desse novo cenário cultural e social, a partir da compreensão de que as inovações não decorrem das tecnologias em si, mas são implementadas processualmente pelos seus usuários.

Para a disciplina de História, área crucial na formação da cidadania e na construção das identidades, inserir as tecnologias em suas aulas, interligando a escola à cultura digital, parece ser ainda mais necessário. O professor dessa disciplina deve, por essa razão, se apropriar das tecnologias digitais e dos novos saberes construídos com sua mediação, refletindo sobre elas, analisando como essas ferramentas podem ser usadas para dinamizar o ensino dessa disciplina e ampliar o repertório cultural dos alunos, questionando as diferenças, desigualdades sociais e culturais e promovendo a cidadania na escola.

Este artigo busca, portanto, sob a perspectiva teórica do Estudos Culturais, discutir a cultura digital que configura o contexto contemporâneo, refletindo sobre a aproximação entre as tecnologias digitais, marca preponderante desse cenário, a escola e o ensino de História, a partir da incorporação desses artefatos na prática cotidiana escolar. Ao longo do percurso discursivo busca-se refletir acerca do seguinte questionamento: como incorporar as tecnologias digitais na sala de aula, aproximando a escola do cotidiano do aluno, de modo a contribuir para o desenvolvimento de sua autonomia, autoria, criticidade e criatividade?
* Mestra em Ensino pelo Programa de Pós-Graduação em Ensino (UERN/ UFERSA/IFRN). Coordenadora do Programa de Formação Continuada de Professores para a inserção das Tecnologias da Informação e Comunicação na sala de aula. Professora de Língua Portuguesa e Inglesa no Ensino Fundamental e Médio da Rede Pública estadual e municipal, em Mossoró-RN. Membro do Grupo de Pesquisa Imagens e Ensino: percepções, métodos e fontes (CNPq/UFERSA).

Contato: socsouza@hotmail.com

** Pós-Doutor em História (PNPD-CAPES/UFPR). Doutor em História pela Universidade Federal de Santa Catarina (UFSC). Professor da Universidade do Estado do Rio Grande do Norte (UERN). Professor do Programa de Pós-Graduação em Ensino (UERN/UFERSA/IFRN). Coordenador do Grupo de Pesquisa Imagens e Ensino: percepções, métodos e fontes (CNPq/UFERSA).

Contato: professor@tamanini.com.br

*** Pós-Doutor em Educação pela Universidade do Estado do Rio de Janeiro (UERJ/CNPq). Doutor em Educação pela Universidade Federal da Paraíba (UFPB). Professor da Universidade do Estado do Rio Grande do Norte (UERN). Professor do Programa de Pós-Graduação em Ensino (UERN/UFERSA/IFRN). Coordenador do Grupo de Pesquisa Contexto e Educação (CNPq/ UERN).

Contato: maccolle@hotmail.com 
O texto, que consiste em um estudo bibliográfico, é composto de duas partes. Na primeira, é feita uma reflexão sobre a configuração da sociedade atual, na qual se discute os conceitos de ciberespaço e cibercultura e os efeitos das tecnologias digitais na sociedade e na educação, com um recorte no ensino de História. Em seguida, o estudo aborda a cultura digital, conceituando-a e caracterizando-a, a partir das mudanças ocorridas nos últimos tempos, causadas pela revolução tecnológica e a consequente centralidade da cultura nesse contexto. Por último, é discutida a configuração que o ensino precisa adotar nesse novo contexto da cultura digital, que é priorizar o olhar crítico sobre as tecnologias, enquanto elemento de consumo, circulação e produção de significações na sociedade, de forma a promover a formação cidadã do aluno.

\section{Tecnologias digitais, ciberespaço e cibercultura: novas possibilidades, novos desafios para a escola}

O homem, desde seus primórdios, vem inventando instrumentos para facilitar sua existência. O surgimento das Tecnologias Digitais da Informação e Comunicação - doravante TDIC - representa esse desejo do homem de desafiar os limites de seu entorno. Entretanto, pode-se afirmar que, nessa tarefa, ele se superou. Nunca antes na história da humanidade, o homem atingiu tanto em tão pouco tempo.

O século XXI tem se mostrado fértil em transformações em vários campos do conhecimento, com desdobramentos em todos os segmentos da vida das pessoas, refletindo-se em novas formas de pensar, se informar, comunicar, relacionar, negociar, aprender e ensinar. Essas mudanças foram ocasionadas, principalmente, pelas TDIC e a denominada revolução técnico-científico-informacional (CASTELLS, 2003). Com as tecnologias digitais, mais especificamente a internet, tempo e espaço são comprimidos, extinguindo-se fronteiras espaciais e temporais. Atualmente, é possível, por exemplo, comunicar-se, ao mesmo tempo, com pessoas que moram em continentes diferentes, além de acessar informações, em tempo real, sobre acontecimentos ocorrendo em lugares geograficamente muito distantes. Vive-se a era do conhecimento, da mobilidade, conectividade e ubiquidade.

Essas transformações originam-se e se concretizam, em sua maior parte, no espaço virtual ou "ciberespaço", termo criado em 1984, por William Gibson, e discutido por Pierre Lévy, filósofo e sociólogo francês, estudioso da internet e seu impacto na sociedade. Em seu livro Cibercultura, Lévy (1999, p. 17) define este termo, afirmando que o ciberespaço engloba tanto a infraestrutura material da comunicação digital como "o universo oceânico de informação que ela abriga, assim como os seres humanos que navegam e alimentam esse universo". 
Assim, o espaço virtual e todo o aparato - computador, informações, pessoas e redes estabelecidas no ambiente virtual - que envolve a comunicação digital entre usuários de todos os lugares do mundo constituem o ciberespaço. Para Lemos (2008, p. 128), o ciberespaço é um "espaço transnacional onde o corpo é suspenso pela abolição do espaço e pelas personas que entram em jogo nos mais diversos meios de sociabilização”. O autor usa, ainda, as expressões "espaço imaginário" e "hipertexto planetário".

Ao revelarem novos modos de se produzir, circular e disseminar informação e conhecimento, bens culturais da sociedade, as tecnologias digitais fazem com que o cenário cultural se torne cada vez mais complexo. O universo de informações vai se mesclando à cultura já existente e constituindo novos conhecimentos, que precisam ser criticamente manipulados. Esse é apenas um dos muitos efeitos que as TDIC vêm provocando.

Ao abordar esse novo cenário contemporâneo e o fenômeno internet, Lévy (1999) também debate outro termo bastante utilizado nesse contexto: o neologismo "cibercultura", que se refere ao "conjunto de técnicas (materiais e intelectuais), de práticas, de atitudes, de modos de pensamento e de valores que se desenvolvem juntamente com o crescimento do ciberespaço" (p. 17). Lemos (2008, p. 1) aduz ser a cibercultura a expressão cultural do encontro entre a sociedade pós-moderna e as tecnologias, em que homem e máquina imbricam-se, definindo-a como "o conjunto de atitudes (apropriação, subterfúgio, ativismo) originadas a partir da união entre as tecnologias informáticas e as mídias de comunicação".

Lemos (2003) cita, como novidades trazidas pelo ciberespaço e parte da cibercultura, as inúmeras práticas comunicacionais (blog, chat, jogos em rede e os do tipo RPG - Role Playing Game -, e-mail, TV, revista e rádio on-line). A internet, segundo ele, não é uma mídia de massa no sentido convencional, já que não existe fluxo "um - todos", mas "todos - todos", e as ações dos usuários não se vinculam a uma atividade específica, pois estar na rede pode significar estar realizando uma infinidade de ações: lendo ou enviando $e$-mail, ouvindo música, batendo papo, escrevendo um post em um blog etc. Para ele, não há abolição de formatos anteriores, mas uma migração, uma reconfiguração, em que o polo de emissão foi liberado, fazendo surgir uma comunicação bidirecional sem regulação de conteúdo. Vive-se, assim, a cultura da convergência de mídias, a multidirecionalidade na comunicação, a produção colaborativa e o compartilhamento de conteúdo. Essas são características da cibercultura ou, em outra denominação, da cultura digital.

A cibercultura constitui, pois, a forma como o homem pensa, sente, age, aprende, ensina e interage no ciberespaço, com reflexos fora dele, modificando-o e sendo por ele modificado. Para Lévy (1999, p. 21), o humano e 
seu ambiente material, bem como os signos e imagens por meio dos quais atribui sentido à vida, são inseparáveis, da mesma forma que não se pode "separar o mundo material e menos ainda sua parte artificial - das ideias por meio das quais os objetos técnicos são concebidos e utilizados, nem dos humanos que os inventam, produzem e utilizam".

Por conseguinte, as tecnologias, enquanto produtos e produtoras da cultura, não podem ser dela dissociadas. Isso requer que os inúmeros conteúdos, atitudes, sentimentos, ideias e informações que circulam no ambiente virtual sejam analisados sob uma perspectiva crítica, tendo em vista que não espelham o real, mas são recortes interpretativos, subjetiva, cultural e historicamente construídos.

Essa nova configuração cultural e social, marcada pelas tecnologias digitais e seus inegáveis benefícios, demanda que a escola insira as tecnologias na sua prática cotidiana. Não se concebe a ideia de que a escola fique à margem das práticas que marcam a cultura do tempo presente, especialmente do ciberespaço e do conteúdo que ali circula. Ser excluído das redes é, segundo Castells (2003), uma das formas mais danosas de exclusão no âmbito econômico e cultural.

No entanto, em face das especificidades desses artefatos, é imprescindível que sejam adotadas novas abordagens e atitudes perante o conhecimento e novos modos de com ele se relacionar. Para isso, os professores precisam se adaptar a esse contexto midiático atual e se apropriar dos artefatos tecnológicos, com vistas a oportunizar aos alunos situações de aprendizagem que os preparem para lidar com uma sociedade complexa e com as demandas da era digital. A questão é: será que esses profissionais estão ou se sentem preparados para essa tarefa?

A preocupação sobre como a incorporação e o uso dessas tecnologias deve se dar na educação vem se refletindo em pesquisas e discussões (LÉVY, 1996, 1999; CASTELLS, 2002, 2003; LEMOS, 2003, 2008, 2009; MATTELART, 2002; ROJO; MOURA, 2012; ARAÚJO; DIEB, 2009; ARAÚJO, 2007; MORAN, 2007, 2015; GIACOMONI; PEREIRA, 2013; ARRUDA, 2013, 2014; BITTENCOURT, 2011), cujos temas vão das teorias, métodos e estratégias adequados para essa inserção até seus efeitos na formação crítica e reflexiva do aluno. Reverberando essa inquietação, Arruda (2013, p. 49), historiador e educador que estuda o uso das tecnologias na educação e no ensino de História, assevera que

[...] a dinâmica das redes sociais e do ciberespaço reconfigura os espaços de ensinar e aprender. Entretanto, resta-nos compreender de que forma estas reconfigurações significam mudanças empíricas nas práticas cotidianas dos professores de História, bem como na construção de saberes históricos mediados por tecnologias digitais. 
Como se percebe, o autor direciona sua preocupação para as mudanças pedagógicas que os professores de História devem adotar ao inserir as tecnologias digitais na sala de aula. Moran (2007), em consonância com Arruda (2013), também defende a necessidade de que, na cultura digital, as práticas pedagógicas sejam ressignificadas, abandonando-se a ideia de aulas baseadas no método expositivo e transmissivista, em que o professor é o detentor do conhecimento e o aluno, o receptor. Para ele, do mesmo modo, não é só a incorporação da tecnologia que vai mudar esse quadro, pois "[...] se ensinar dependesse só de tecnologias, já teríamos achado as melhores soluções há muito tempo. Elas são importantes, mas não resolvem as questões de fundo" (MORAN, 2007, p. 12).

Assume-se, portanto, que não adianta o professor inserir tecnologias para ensinar do mesmo modo que ensinava antes. É preciso que todo o modelo pedagógico, assim como as concepções de ensino, aprendizagem, avaliação, conhecimento, papel do aluno e do professor que têm imperado na escola sejam repensados. Com isso, a inquietação que surge agora é: como então ensinar em um contexto mutável, móvel, ubíquo e interconectado?

Uma vez que o direito à educação e à informação sem qualquer distinção, previsto constitucionalmente, impõe à escola oferecer aos alunos condições para que se desenvolvam de modo pleno, capacitando-os para enfrentar os desafios da contemporaneidade, uma possível resposta à questão acima talvez seja a de que o professor deve, a partir dos artefatos tecnológicos, auxiliar os alunos a se tornarem, simultaneamente, consumidores, produtores e críticos das informações originadas desses artefatos e por eles veiculadas, produto de seu contexto cultural.

$\mathrm{O}$ que se quer com esse estudo é, portanto, refletir sobre a cultura digital atual, o papel das Tecnologias Digitais da Informação e Comunicação nesse cenário e na escola, em especial no ensino de História, buscando favorecer a formação ativa, criativa, pensante e crítica dos alunos. Para isso, é preciso evitar que o olhar sobre as tecnologias digitais, em especial a internet, se foque nestas enquanto técnica, instrumento, ferramenta, procurando, ao contrário, visualizá-las como produto da cultura contemporânea ou, mais especificamente, da cultura das mídias (ARRUDA, 2014, p. 240). Daí a importância de se discutir a cultura digital, a partir de seu conceito e características.

\section{A escola e o ensino de história na cultura digital sob a perspectiva dos estudos culturais}

O homem contemporâneo vive rodeado de tecnologias digitais e em constante conexão com o mundo, o que lhe permite instantaneidade, tanto nas comunicações com as pessoas como no acesso a informações atualizadas. De acordo com Bortolazzo (2016), as relações dos sujeitos com os artefatos digitais (smartphone, computador, ipad 
etc.), têm significado alterações sociais e culturais visíveis na contemporaneidade, uma vez que, com a conexão de milhões de pessoas às redes de informações, suas práticas cotidianas incorporaram certos hábitos criados pelo uso intensivo das tecnologias.

Com base na vertente pós-estruturalista dos estudos culturais, arcabouço teórico desse trabalho, acredita-se que a utilização e a apropriação das tecnologias digitais são produtos culturais de determinada sociedade, pontuadas por uma natureza histórica e contingente (BORTOLAZ$\mathrm{ZO}, 2016)$. Isso porque, em conformidade com Bortolazzo (2016), o pós-estruturalismo parte da ideia de que não há estruturas estáveis e de que a realidade é uma construção social, histórica e subjetiva, de modo que os textos, filmes, imagens, músicas etc., que são produzidos, recepcionados e circulam nesse contexto, veiculam uma pluralidade de sentidos, sendo seus significados instáveis, negociáveis, sempre em processo. Para Canclini (2005, p. 34, tradução nossa), esse "conjunto de processos sociais de produção, circulação e consumo da significação na vida social" configura a cultura.

Para Hall (1997, p. 16), relevante teórico e consolidador do campo dos Estudos Culturais, o homem é um ser interpretativo, instituidor de sentido e, para definir o que significam as coisas, para codificar, organizar e regular seu comportamento em relação aos outros, utiliza sistemas de significado, que dão sentido às suas ações, permitindo, ao mesmo tempo, a interpretação significativa das ações alheias. Conforme o autor, esses sistemas constituem as culturas e ajudam a garantir que toda ação social seja cultural, por expressar ou comunicar um significado. A noção de cultura, na concepção de Hall (1997), pode ser comparada a "significados compartilhados", haja vista os membros de uma mesma cultura partilharem entre si códigos culturais, isto é, conceitos, ideias e imagens, que lhes possibilitam similitude no modo de sentir, pensar e interpretar o mundo.

Hall (1997) assevera, ainda, que a cultura possui duas dimensões: uma substantiva, por meio da qual age na estrutura empírica da realidade e na organização das atividades, instituições e relações culturais, em qualquer momento histórico; e uma epistemológica, constituída por meio da linguagem e denominada "virada cultural", relativa à posição da cultura no que tange às questões de conhecimento e conceitualização, ou seja, ao papel exercido pela cultura na transformação da compreensão, explicação e dos modelos teóricos com os quais o homem representa o mundo. Dito de outro modo, a cultura, na perspectiva de Hall (1997), engloba tanto os fenômenos da vida social como os modelos cognitivos do ser humano.

Costa, Silveira e Sommer (2003, p. 38) esclarecem que a virada cultural constitui o

[...] poder instituidor de que são dotados os discursos circulantes no circuito da cultura.
1 "[...] conjunto de procesos sociales de producción, circulación y consumo de la significación en la vida social”. 
Um noticiário de televisão, as imagens, gráficos etc. de um livro didático ou as músicas de um grupo de rock, por exemplo, não são apenas manifestações culturais. Eles são artefatos produtivos, são práticas de representação, inventam sentidos que circulam e operam nas arenas culturais onde o significado é negociado e as hierarquias são estabelecidas.

Nessa linha, pode-se afirmar que há uma dimensão cultural em todas as instituições e práticas sociais: "cada instituição ou atividade social gera e requer seu próprio universo distinto de significados e práticas - sua própria cultura" (HALL, 1997, p. 32). Em função disso, a cultura é um elemento central em todos os segmentos da vida em sociedade, fazendo-se presente tanto nas ações do indivíduo como nos modelos por ele utilizados para compreender e representar a realidade que o cerca, por meio do discurso (especialmente o midiático) e sua natureza produtiva e constitutiva das práticas cotidianas, das identidades e do modo de ver o mundo.

Na sociedade moderna tardia, a cultura assumiu um papel de relevância ímpar, em decorrência da expansão dos meios de produção, circulação e troca cultural, intermediada pelas tecnologias e pela "revolução da informação" (HALL, 1997, p. 17). As tecnologias favoreceram a síntese do tempo e do espaço, a chamada compressão tempo-espaço, o que introduziu mudanças na consciência das pessoas (HALL, 1997). Os fenômenos provocados pelas tecnologias digitais revolucionam as culturas em nível global, impactando as formas de os sujeitos viverem, pensarem, sentirem e interpretarem o seu contexto local. Desse modo, não há que se falar mais em uma identidade cultural exclusivamente local, sem conexão com o global, mas em uma identidade cultural hibridizada, heterogênea, síntese de elementos de múltiplas culturas, que não se limita nem se reduz a nenhuma delas (HEINSFELD; PISCHETOLA, 2017). Por conseguinte, "a realidade, desde sempre mediada pela linguagem e os códigos criados por ela, é hoje mediada também pelas culturas e pelas linguagens das mídias" (id., ibid., p. 1354-1355).

Em arremate, importa destacar que, por existirem sistemas conceituais distintos, produzidos e reproduzidos por grupos e contextos sociais igualmente distintos, não se pode universalizar os significados culturais. Nessa perspectiva, por possibilitar produzir os sistemas de significado usados para dar sentido ao mundo, a cultura situa o homem enquanto sujeito, ajudando-o a definir quem ele é e quem ele pode ser (HALL, 1997), função que a torna foco constante de embates de poder e regulação. Mas, finalmente, o que seria exatamente a cultura digital e como ela se configura? 


\subsection{Cultura digital: conceito e caracterização}

Conforme vem sendo discutido, a cultura constitui o universo de significados e práticas produzidos sobre e pela ação humana dentro de um dado contexto social. Destarte, o homem cria objetos e formas, elabora conceitos, enfim, dá vida e significado às coisas que o rodeiam. Ao se abordar as transformações sociais do século XXI, salta à vista de imediato a forte presença das Tecnologias Digitais da Informação e Comunicação em todos os âmbitos da atividade humana, atuando, simultaneamente, como produtos e produtoras de novas maneiras de comunicar, informar, sentir, aprender, ensinar, pensar, trabalhar e se relacionar, gerando, dessa forma, mudanças culturais na sociedade, ao alterar as práticas relacionais no mundo contemporâneo.

O conjunto dessas mudanças sociais, políticas e econômicas, causadas pela ruptura nos modos de conceber, (re)produzir e difundir a informação e que vêm alterando as relações culturais no que se refere ao entrosamento entre as pessoas e as tecnologias digitais, configura a denominada cultura digital na atualidade (HEINSFELD; PISCHETOLA, 2017). Esse processo, segundo Heinsfeld e Pischetola (2017, p. 1353), dá-se da seguinte maneira:

A cultura unificada e hegemônica toma a forma de novas identificações heterogêneas e adaptações localizadas, de hibridismos que sintetizam elementos de culturas múltiplas, não se limitando ou se reduzindo a nenhuma delas. Posto isto, torna-se mandatório compreender que revoluções culturais globais causam impacto sobre os modos de viver, seus sentidos e ressignificações, aspirações e mesmo sobre culturas locais, e que geram, como frutos, mudanças sociais e deslocamentos culturais.

Essa nova configuração de pensamentos, práticas e conceitos, englobando tecnologias digitais, diferentes sistemas de significação e comunicação descritivos das formas de vida contemporânea (HEINSFELD; PISCHETOLA, 2017), conformam, portanto, a cultura digital.

É imperativo deixar evidente aqui que, quando se fala em cultura digital, faz-se referência a uma adaptação da cultura ao contexto digital atualmente vivido, e não vice-versa. Por isso, o conceito de cultura está diretamente vinculado tanto à "alteração das relações culturais quanto ao entrosamento entre sujeitos e mídias de informação e comunicação, surgida da ruptura na forma como a informação era até então concebida, (re)produzida e difundida" (HEINSFELD; PISCHETOLA, 2017, p. 1352).

Destarte, na visão de Heinsfeld e Pischetola (2017), a reestruturação da sociedade, possibilitada pela conectividade e marcada pela transversalidade, descentralização 
e interatividade, é o que caracteriza a cultura digital. Em acréscimo, também podem ser ressaltados como elementos caracterizadores desse novo cenário: intensa presença das tecnologias digitais, notadamente da internet; instantaneidade da comunicação; acesso, produção e compartilhamento de conteúdo de forma célere, mediados pelos artefatos digitais; ubiquidade; hibridismo; conexão rápida e o "apagamento das linhas limítrofes entre o que se considera 'real' e o 'virtual', convergindo para a desterritorialidade" (HEINSFELD; PISCHETOLA, 2017, p. 1352). As autoras enfatizam, ainda, que a mudança não se restringe ao técnico, mas ultrapassa-o, dialogando com conceitos como a ciberdemocracia, inclusão, ética hacker, colaboração, horizontalidade, inteligência coletiva e descentralização, espraiando-se por todas as esferas da vida humana. Constitui uma revolução cultural, fulcrada em uma nova realidade sociocultural, em que se imbricam ambientes de interação social convencionais e as tecnologias digitais.

Nessa vertente, Bortolazzo (2016) adverte sobre o perigo de se cair no determinismo técnico, ao se considerar a cultura digital como algo completamente novo, originado apenas dos avanços tecnológicos, esquecendo-se do aspecto social e das intencionalidades que permeiam esse processo e que o digital engloba, além dos efeitos e possibilidades de uma dada tecnologia, os modos de pensar e realizar determinadas atividades relacionadas a essa tecnologia e sua existência.

O conceito de cultura digital pode ser articulado ao de cibercultura, debatido por Lévy (1999), ou ao de era digital ou era da informação (CASTELLS, 2002), visto que todos atuam como demarcadores de um contexto onde as relações entre homem, informação e máquina são mediadas por artefatos digitais (BORTOLAZZO, 2016). Bortolazzo (2016) asserta que a cultura digital é produzida por um conjunto de elementos vinculados ao digital (sites pessoais ou institucionais, redes sociais, artefatos digitais, bem como as relações que os sujeitos mantêm), incluindo, nesse universo, conceitos e ideias. $\mathrm{O}$ autor esclarece também que a emergência da expressão cultura digital adveio da comunicação dominada pelas tecnologias digitais, na qual o homem participa como produtor, consumidor e disseminador e que tem se inserido na vida cotidiana, intervindo nas relações estabelecidas com a realidade material e simbólica que o cerca.

Cabe ressaltar, também, que na cultura digital, a interdisciplinaridade prevalece, pois as tecnologias, além de interagir com várias disciplinas (Educação, Sociologia, História, Filosofia etc.), proporciona a articulação entre elas, constituindo-se seu uso, por conseguinte, uma alternativa interessante para a atividade pedagógica desenvolvida na escola. Por se configurarem como inovadores, complexos e multidimensionais, os artefatos digitais, em especial o ciberespaço e seus recursos informacionais, comunicacionais e interacionais, direcionam o olhar do aluno 
para a complexidade do mundo, o que lhe permite, por isso mesmo, pensar de forma complexa.

Ademais, face ao contexto da cultura digital, Morin (2000) afirma ser necessário enfrentar as incertezas e os imprevistos ligados ao conhecimento, não havendo, para isso, estratégia melhor do que o ensino interdisciplinar mediado pelos artefatos digitais que já fazem parte do cotidiano do aluno fora da escola e que, por suas variadas características, refletem a interligação entre os diferentes saberes.

Assim como as outras disciplinas do currículo, o ensino de História não pode se desvincular do contexto real, "das práticas cotidianas, das representações culturais, das práticas discursivas, do imaginário" (OLIVEIRA, 2013, p. 214), afinal, a história do tempo presente também compõe o currículo dessa disciplina. Ao ensinar História de modo fragmentado, o professor afasta-se, e ao acontecimento, de seu contexto histórico, cultural e social, coibindo o aluno de desenvolver sua criticidade perante o fato apresentado.

O homem constitui-se enquanto ser complexo, multifacetado, independentemente das mudanças por que passe a sociedade e a escola. Ensinar História na cultura digital deve ser ensinar a viver a complexidade, buscando compreender e respeitar a diversidade dos grupos e pessoas que constroem ou construíram a história. Para isso, é necessário recorrer às várias disciplinas curriculares, interligando seus saberes, objetivando promover uma atitude crítica, pensante, ativa e criativa no aluno, em harmonia com a realidade complexa e multifacetada em que ele vive.

\subsection{Ensinar na cultura digital: novos cenários, outros olhares}

Com a revolução cultural iniciada no século XX, as tecnologias digitais assumiram uma posição relevante na modernidade tardia (HALL, 1997). Os Estudos Culturais, ao tentar compreender os processos comunicativos presentes nessas transformações, consideram o receptor midiático como um sujeito ativo, um agente nesse processo, atento às contradições sociais e conflitos culturais que as tecnologias digitais potencializam (HEINSFELD; PISCHETOLA, 2017).

No âmbito educacional, os Estudos Culturais possibilitam reflexões a respeito de questões que atingem a educação no século XXI, tanto no que se refere às possibilidades quanto aos desafios que o uso, consumo e produção dos artefatos digitais podem provocar. Sendo a escola o espaço formal de educar para a vida e para o exercício da cidadania, deve ser um lugar de descobertas, de construção de significados e de reflexões. A sala de aula deve proporcionar o desenvolvimento da autonomia do aluno e sua formação enquanto sujeito crítico e criativo, capaz de atuar, reflexivamente, sobre o mundo que o cerca.

$\mathrm{Na}$ perspectiva dos Estudos Culturais, a incorporação das tecnologias digitais na escola contribui para que 
o aluno aprenda a lidar criticamente, como receptor, com as informações por elas veiculadas, situando-se, ao mesmo tempo, como produtor e disseminador dos conteúdos que por elas circulam, sendo capaz de desvelar os discursos impostos como verdadeiros e únicos, representativos de interesses histórica e culturalmente determinados.

As TDIC, em especial a internet, abrem inúmeras e ímpares possibilidades de sentir, pensar, ler, escrever, comunicar e interpretar o mundo, os objetos e as pessoas, sendo sua inserção na prática pedagógica de inegável urgência, como já mencionado alhures. Logo, são inúmeros os benefícios que as tecnologias digitais apresentam em todas as esferas da vida humana, que vão desde a democratização do saber até a construção colaborativa do conhecimento, ambos constituindo-se fatores conducentes para o exercício da cidadania. Lévy (1996), ao citar as vantagens do ciberespaço, caracteriza-o como lugar onde o homem se realiza, supera as diferenças e, por meio da inteligência coletiva, amplia a colaboração e a troca de saberes, experimentando novas práticas democráticas e exercendo, destarte, sua cidadania. Lévy (1999) também aborda o papel das tecnologias intelectuais e sua importância no favorecimento de novos modos de acessar a informação e construir conhecimento.

As tecnologias digitais apresentam, portanto, possibilidades imponderáveis para o exercício da democracia e a ampliação do espaço público. Lemos (2009, p. 10), ao caracterizar o contexto midiático contemporâneo, denomina-o de nova esfera conversacional, inaugurada com as mídias pós-massivas. O cenário comunicacional foi reconfigurado, dando lugar a uma cultura conversacional, mais do que informacional, apoiada no diálogo e na ampliação da participação pública na ação política, já que a conversação aberta e livre dá base à ação política. Essa atribuição pós-massiva das mídias contrapõe-se à massiva, que está relacionada aos meios de comunicação de massa do fim do século XIX e tem como base o fluxo centralizado de informações, dominado por grandes empresas de comunicação (LEMOS, 2009). Para Lemos (2009, p. 12), a lógica comunicacional, característica da cultura digital contemporânea, "[...] cada vez mais banal e planetária, [...] se constrói na nova esfera pública que é o ciberespaço, em se fazendo, através da produção, do compartilhamento e da distribuição de conteúdo".

Entretanto, apesar dos inúmeros e inegáveis benefícios que as tecnologias digitais proporcionam à sociedade moderna tardia, elas também apresentam algumas negatividades e desafios, a exemplo da quantidade excessiva de informações e conteúdos na rede, que acaba por dificultar o estabelecimento de relações entre esses conteúdos e informações, impedindo que se interprete, com criticidade, seus possíveis significados ocultos. Entre os desafios mais marcantes, na visão de Pischetola e Heinsfeld (2017, p. 1356), estão a "necessidade de a escola propiciar o 
desenvolvimento das habilidades necessárias à atuação cidadã em sociedade e a urgência de serem exploradas as potencialidades das redes digitais".

Arruda (2013), ao relacionar cultura, ensino de História e ciberespaço, enfatiza como vantagem das tecnologias digitais a instantaneidade das trocas culturais. Para este autor, as negatividades nas relações sociais e culturais que a rede potencializa não reduzem o efeito dos benefícios, pois sempre fizeram parte da história humana, cabendo ao Estado, via educação formal, intermediar a formação cidadã para o uso responsável e ético do ciberespaço (ARRUDA, 2013). No que tange ao papel dos artefatos digitais no ensino de História, Arruda (2014) destaca os novos olhares que eles permitem lançar sobre o passado, ao reconfigurarem a dimensão da memória e do acontecimento, assim como a ampliação do acesso à produção da cultura, possibilitada pela internet, apesar de reforçar a necessidade da análise crítica dos contextos onde tais informações e conteúdos são gerados.

Com relação aos aspectos negativos, Arruda (2013), embora ressalte as vantagens do ciberespaço, como a construção colaborativa e democrática do conhecimento, admite ser este um "espaço construído pelo homem e, como tal, permeado de seus paradoxos, contradições e relações de poder" (ARRUDA, 2013, p. 38), logo, cultural e socialmente construído. Outro ponto a ser refletido é a falta de criticidade quanto às informações veiculadas pelas mídias digitais que, em geral, não são questionadas, mas vistas como verdades únicas, tanto pelos professores como pelos alunos.

Em função disso, não há como negar a necessidade de um uso pedagógico reflexivo desses artefatos digitais, a partir de um olhar crítico e da reflexão acerca dos discursos e sentidos que justificam a cultura daqueles que regulam os conteúdos que neles circulam ou são produzidos e consumidos. Programas de TV, música, internet e filmes comprovam como as tecnologias digitais, enquanto produtos e produtoras de cultura, são reguladas com vistas a formar um público com preferências e opiniões homogêneas (TERUYA, 2009).

Para combater tal utilização acrítica, contudo, faz-se mister conhecer as potencialidades e negatividades das tecnologias digitais, por meio de um uso crítico, autoral, criativo e reflexivo. O professor deve desenvolver atividades que permitam aos alunos não apenas atuarem como consumidores, mas como produtores, construindo conteúdo colaborativamente, assumindo uma postura ativa na tessitura social, atuando, desse modo, como agente de seu percurso histórico.

Os artefatos digitais estão tão incorporados à vida social, alterando a estrutura e funcionamento das instituições e das práticas sociais, que seus efeitos estão se invisibilizando cada vez mais. Smartphone, redes sociais (Facebook, Instagram, Twitter, WhatsApp, YouTube etc.), 
blogs, enciclopédia colaborativas, jogos digitais, webquest, podcast, entre outros, são apenas alguns exemplos de artefatos digitais, aplicativos e dispositivos, presentes na ambiência da cultura digital que, de forma despercebida, vão gerando novas relações e maneiras de interpretar a realidade. O perigo encontra-se precisamente nessa invisibilização, que leva ao uso acrítico, sem questionar as intenções subjacentes a cada tecnologia, os fins de sua criação.

A escola precisa, portanto, promover discussões que instiguem a reflexão acerca dos impactos dessas tecnologias na cultura e na sociedade, bem como da ressignificação da interação do homem com os artefatos digitais e com seus pares. Nesse sentido, é fundamental vislumbrar esses artefatos digitais, bem como a informação e comunicação por eles possibilitadas, como bens culturais, elementos da esfera pública, produtos e produtores da cultura.

Inserir as tecnologias digitais na prática pedagógica é, como já mencionado, necessário; todavia, essa inserção deve ser feita com ética, criticidade e de forma responsável, para não cair em um discurso tecnocrático, repleto de promessas de democratizar as relações sociais, superar as injustiças e solucionar os conflitos sociais por meio de dispositivos técnicos (MATTELART, 2002). Esse tipo de discurso ignora que os modos como as técnicas são implementadas e socialmente estruturadas, seus usos e funções, são histórica e socialmente determinados pelas estruturas de poder predominantes em cada realidade e momento histórico.

Teruya (2009) sustenta que a identidade cultural é expressa pela comunicação, sendo esta, por isso mesmo, o elemento central da cultura e "ferramenta simbólica para organizar as nossas relações com o outro" (p. 156). Por isso mesmo, é preciso criticidade no manuseio, na escola, das comunicações e informações que circulam por meio das TDIC. O debate na sala de aula sobre as complexas relações entre produção, mensagem, recepção e resposta no percurso comunicacional é indispensável, tendo em vista a mediação que as mensagens veiculadas pelas mídias sofrem em diferentes contextos e realidades culturais (TERUYA, 2009).

Desse modo, ao utilizar as tecnologias digitais, com ênfase na internet e seus recursos comunicacionais, informacionais e interacionais, o professor deve considerar as relações intrínsecas entre os saberes e as diferenças culturais e identitárias existentes na sociedade e dentro da sala de aula, buscando, por essa razão, desenvolver um trabalho interdisciplinar e que leve em conta as múltiplas linguagens e a diversidade social, racial, regional, étnica e de gênero dos alunos.

Em sinergia com a assertiva de que a mera incorporação de tecnologias digitais na escola não significa mudanças nos processos de ensinar e aprender, Martín-Barbeiro (2000, p. 61), expoente dos Estudos Culturais e estudioso da comunicação e da cultura, aduz ser preciso modificar o 
modelo comunicativo-pedagógico que predomina no sistema escolar, já que este é "vertical e autoritário na relação professor-aluno, e linear sequencial no aprendizado". Para este teórico, "enquanto permanecer a verticalidade na relação docente e a sequencialidade no modelo pedagógico, não haverá tecnologia capaz de tirar a escola do autismo em que vive", sendo, assim, indispensável partir desses problemas antes de falar de tecnologias (MARTÍN-BARBERO, 2000, p. 52-53).

Martín-Barbeiro ressalta, ainda, o fato de a escola não ser mais o único espaço de legitimação do saber, já que, com as tecnologias digitais, especialmente a internet, "os saberes circulam por outros canais, difusos e descentralizados" (2000, p. 55), sendo esta diversificação e difusão do conhecimento fora da escola um dos maiores desafios apresentados pelo mundo comunicacional à educação. $\mathrm{O}$ aluno que frequenta a sala de aula não é um receptáculo vazio, mas traz consigo linguagens e saberes, às vezes até mais atualizados do que os do professor, que circulam no contexto onde vive (MARTÍN-BARBEIRO, 2000).

Como vem sendo discutido, ao longo desse trabalho, a escola vive hoje imersa na cultura digital. Nesse contexto, não há mais espaço para um ensino unidirecional e verticalizado. Urge formar para a autonomia, democracia e cidadania, ajudando a desenvolver nos jovens uma mentalidade crítica, que respeite a heterogeneidade (MARTÍN-BARBEIRO, 2000). Mas, como atesta Martín-Barbeiro, só se aprende a ser democrático em escolas que veem a diferença como riqueza e que respeitam o direito de seus cidadãos se expressarem, bem como só se constrói cidadania ensinando os alunos "a ler o mundo de maneira cidadã" (2000, p. 60).

Diante de tudo o que foi exposto, conclui-se que há necessidade de uma escola aberta à diversidade, com um novo modelo de comunicação, multidirecional e descentralizado, de todos para todos, que defenda o uso das tecnologias digitais de modo criativo, colaborativo e crítico, um espaço em que as pessoas possam pensar "com sua cabeça e não com as ideias que circulam ao seu redor" (MARTÍN-BARBEIRO, 2000, p. 60).

\section{Considerações finais}

No contexto da cultura digital, pautado pela presença das tecnologias digitais, em especial a internet, e por elas mediado, as distâncias culturais e sociais vêm sendo reduzidas. Caracterizado pelas negociações dialógicas de significação entre os artefatos digitais, o homem e a sociedade que o cerca, esse novo cenário proporciona a democratização da informação e do conhecimento, favorece trocas culturais, reconfigura a relação do homem com o saber e oferece inúmeras e inéditas possibilidades de exercício da cidadania.

Por isso mesmo, a escola, como espaço de formação de jovens e crianças que já nascem imersos na cibercultura, 
precisa inserir-se na cultura digital, abrindo-se à incorporação das tecnologias enquanto produtos e produtoras dos sentidos que reconfiguram o modo de viver, pensar, sentir e se relacionar no mundo contemporâneo. Esse processo, entretanto, notadamente no ensino de História, não deve ser reduzido ao mero tecnicismo ou a uma visão limitada das tecnologias digitais na prática pedagógica, desconsiderando as potencialidades desses artefatos na formação de protagonistas da história, consumidores e produtores de conteúdos em e por meio da rede e de outros dispositivos digitais.

Foi discutida, ao longo desse estudo, a configuração da atual sociedade, denominada cultura digital, sob a perspectiva dos Estudos Culturais, reconhecendo-se os efeitos de suas marcas constitutivas - presenças das tecnologias digitais, fluidez, mobilidade, conectividade, transitoriedade, imediatismo, hibridismo cultural, diversidade, linguagens e gêneros textuais múltiplos e inéditos, colaboração, instantaneidade nas comunicações e informações, ciberdemocracia, ciberespaço etc. - nas formas de vida na contemporaneidade.

Para a pergunta feita na introdução desse texto - como incorporar as tecnologias digitais na sala de aula, aproximando a escola do cotidiano do aluno, de modo a contribuir para o desenvolvimento de sua autonomia, autoria, criticidade e criatividade? -, não há uma resposta fechada, mas tentativas de caminhos que, talvez, possam aproximar a escola da cultura digital e do conhecimento diversificado e difuso que circula fora de seus muros. Para que isso aconteça, contudo, a escola, e com ela o ensino de História, não podem se eximir das mudanças, do novo, devendo adotar posturas pedagógicas abertas e pautadas na complexidade do ensinar e do aprender e na relação não-verticalizada professor-aluno e aluno-aluno. É imperativo, portanto, que a escola, seus métodos e o professor mudem.

Em conformidade com o debate que, por ora, se encerra, rejeita-se uma inserção dos artefatos culturais alijada da reconfiguração do modelo pedagógico predominante, centrado em um discurso unidirecional e centralizador. O ensino com tecnologias digitais deve, desse modo, promover a produção, apropriação e consumo dos conteúdos midiáticos, de forma crítica, analisando sempre os fins a eles subjacentes.

Sendo a comunicação o principal elemento simbólico da cultura, e considerando que as tecnologias digitais influenciam e são influenciadas por ela, os autores utilizados como base teórica nesse artigo também defendem, no manuseio e consumo dos conteúdos produzidos e veiculados por meio das mídias digitais, o uso do olhar crítico, principalmente no âmbito escolar. Isto porque, como foi colocado, não são as tecnologias, por suas características intrínsecas, que modificam as práticas sociais e culturais, mas os sujeitos que as manipulam, podendo estes negociar com os discursos e representações culturais veiculados 
pelas mídias, deixando de ser meros consumidores e receptores, o que evidencia mais fortemente a necessidade de que o professor as incorpore, de modo crítico, na sua prática docente.

Defende-se, por conseguinte, um ensino de História baseado no diálogo, na multidirecionalidade e na descentralização; um ensino voltado ao desenvolvimento da autoria, autonomia, criticidade, criatividade e da participação ativa do aluno na sua relação com o mundo, com o outro e com os objetos que o rodeiam, como elementos da formação para a cidadania. Apenas assim, a escola estará formando sujeitos capazes de construir sua própria história.

\section{Referências}

ARAÚJO, Júlio C.; DIEB, M. (Orgs.). Letramentos na web: gêneros, interação e ensino. Fortaleza: Edições UFC, 2009 .

ARAÚJO, Júlio C. (Org.). Internet e ensino: novos gêneros, outros desafios. Rio de Janeiro: Lucerna, 2007.

ARRUDA, Eucídio Pimenta. Cultura e ensino de História na perspectiva das redes sociais e do ciberespaço. In: SILVA, Cristiani Bereta da; ZAMBONI, Ernesta (Orgs.). Ensino de história, memória e culturas. Curitiba, PR: CRV, 2013. p. 35-53.

ARRUDA, Eucídio Pimenta. Aprender História com jogos digitais em rede: possibilidades e desafios para os professores. In: MAGALHÃES, Marcelo et. al. (Orgs.). Ensino de História: usos do passado, memória e mídia. Rio de janeiro: FGV Editora, 2014. p. 239-253.

BITTENCOURT, Circe M. F. Ensino de História: fundamentos e métodos. 4. ed. São Paulo: Cortez, 2011.

BORTOLAZZO, Sandro Faccin. O imperativo da cultura digital: entre novas tecnologias e estudos culturais. Revista Cadernos de Comunicação, Santa Maria, v. 20, n. 1, art. 1, p. 1-24, jan/abr. 2016. Disponível em: https://periodicos.ufsm.br/ccomunicacao/article/viewFile/ 22133/pdf. Acesso em: 13 jan. 2019.

CANCLINI, Nestor. G. Diferentes, desiguales y desconectados: mapas de la interculturalidad. Barcelona: Gedisa, 2005. Disponível em: https://teoriasantropologicasucr. files.wordpress.com/2011/o5/garcia-canclini-nestor-diferentes-desiguales-y-desconectados-mapas-de-la-interculturalidad.pdf. Acesso em: 12 jan. 2019.

CASTELLS, Manuel. A sociedade em rede. São Paulo: Paz e Terra, 2002. 
CASTELLS, Manuel. A Galáxia da internet: reflexões sobre a internet, os negócios e a sociedade. Rio de Janeiro: Jorge Zahar Ed., 2003.

COSTA, Marisa Vorraber; SILVEIRA, Rosa Hessel; SOMMER, Luís Henrique. Estudos culturais, educação e pedagogia. Revista Brasileira de Educação, n. 23, p. 36-61, maio/ jun/jul/ago. 2003. Disponível em: http://www.scielo.br/pdf/rbedu/n23/n23ao3. Acesso em: o8 jan. 2019.

GIACOMONI, Marcello Paniz; PEREIRA, Nilton Mullet (Orgs.). Jogos e ensino de História. Porto Alegre: Evangraf, 2013.

HALL, Stuart. A centralidade da cultura: notas sobre as revoluções culturais do nosso tempo. Educação e Realidade, Porto Alegre, v. 22, no 2, p. 15-46, jul./dez. 1997. Disponível em: https://seer.ufrgs.br/educacaoerealidade/ article/view/71361. Acesso em: 07 jan. 2019.

HEINSFELD, Bruna Damiana; PISCHETOLA, Magda. Cultura digital e educação: uma leitura dos estudos culturais sobre os desafios da contemporaneidade. Revista Ibero-Americana de Estudos em Educação, Araraquara, v. 12, n. esp. 2, p. 1349-1371, ago./2017. Disponível em: http://dx.doi.org/10.21723/riaee.v12.n.esp.2.10301. Acesso em: 10 jan. 2019.

LEMOS, André. Cibercultura: tecnologia e vida social na cultura contemporânea. 4.ed. Porto Alegre: Sulina, 2008.

LEMOS, André. Nova esfera Conversacional (prefácio). In: DIMAS A. Künsch, D. A. et al. Esfera pública, redes e jornalismo. Rio de Janeiro: Ed. e-Papers, 2009. p. 9-30. Disponível em: https://www.academia.edu/1771453/ Nova_esfera_conversacional. Acesso em: 05 jan. 2019.

LEMOS, André. Cibercultura: alguns pontos para compreender a nossa época. In: LEMOS, André; CUNHA, Paulo (Orgs.). Olhares sobre a cibercultura. Porto Alegre/ RS: Sulina, 2003. p. 11-23.

LÉVY, Pierre. Cibercultura. São Paulo: Editora 34, 1999.

LÉVY, Pierre. O que é o virtual. São Paulo: editora 34, 1996.

MARTÍN-BARBERO, Jesús. Desafios culturais da comunicação à educação. Revista Comunicação e Educação, USP, São Paulo, n. 18, p. 51-61, maio-ago. 2000. Disponível em: http://www.revistas.usp.br/comueduc/article/ view/36920/39642. Acesso em: 12 jan. 2019.

MATTELART, Armand. História da sociedade da informação. São Paulo: Loyola, 2002. 
MORAN, José Manuel. Mudando a educação com metodologias ativas. 2015. Disponível em: http://www2. eca.usp.br/moran/wp-content/uploads/2013/12/mudando_moran.pdf. Acesso em: 02 jun. 2018.

MORAN, José Manuel. Ensino e aprendizagem inovadores com apoio de tecnologias. In: MORAN, José Manuel; MASETTO, Marcos T.; BEHRENS, Marilda A. Novas tecnologias e mediações pedagógicas. 13. ed. São Paulo: Papirus, 2013. p. 11-65.

MORIN, Edgar. Os sete saberes necessários à educação do futuro. 2. ed. São Paulo: Cortez, 2000.

OLIVEIRA, Nucia A. S. Ensino de História e interdisciplinaridade. In: SILVA, Cristiani Bereta da; ZAMBONI, Ernesta (Orgs.). Ensino de história, memória e culturas. Curitiba, PR: CRV, 2013. p. 209-227.

ROJO, Roxane Helena R.; MOURA, Eduardo (Orgs.). Multiletramentos na escola. São Paulo: Parábola Editorial, 2012.

TERUYA, Teresa Kazuko. Sobre mídia, educação e estudos culturais. In. MACIEL, Lizete Shizue Bomura; MORI, Nerli Nonato Ribeiro (Orgs.). Pesquisa em educação: múltiplos olhares. Maringá: Eduem, 2009. p. 151-165.

Recebido em: 06/02/2019 Aprovado em: 24/02/2020 Publicado em: 01/04/2020 